\title{
Improvement of Bread Quality by Adding Wheat Germ Fermented with Lactobacillus plantarum dy-1
}

\author{
Yansheng Zhao, ${ }^{1}$ Jiayan Zhang, ${ }^{1}$ Yixing Wei, ${ }^{1}$ Lianzhong $A i,{ }^{2}$ Dong Ying, \\ and Xiang Xiao (iD \\ ${ }^{1}$ School of Food and Biological Engineering, Jiangsu University, Zhenjiang 212013, China \\ ${ }^{2}$ School of Medical Instrument and Food Engineering, University of Shanghai for Science and Technology, \\ Shanghai 200093, China
}

Correspondence should be addressed to Xiang Xiao; xiaoxiang1@aliyun.com

Received 20 January 2020; Accepted 9 March 2020; Published 7 April 2020

Academic Editor: Flora V. Romeo

Copyright (c) 2020 Yansheng Zhao et al. This is an open access article distributed under the Creative Commons Attribution License, which permits unrestricted use, distribution, and reproduction in any medium, provided the original work is properly cited.

\begin{abstract}
Fermentation has been considered as an effective way to improve the nutritional and sensory quality of food materials. In this paper, fermented wheat germ (FWG) was prepared by fermentation with Lactobacillus plantarum dy-1 and added as an ingredient in bread making for nutrition and quality improvement. The amounts ranged from $1 \%$ to $6 \%$ of FWG were added into ingredients for bread making, the similar amounts of raw wheat germ (RWG) were used as control, and the wheat flour without germ addition was used as blank. Then, bread quality was evaluated through nutrition, texture, and flavor analyses. The results showed that $4 \%$ of FWG addition had the ability to increase the specific volume, slow down the aging process, and improve the color and luster of bread. A significant increase in free amino acid content was observed in the FWG bread, which could be helpful to enrich the flavor substances in bread. The flavor analysis of bread showed that more volatile compounds mainly alcohols and aldehydes were present in FWG bread compared with RWG bread. In the fermentation process, the pH value was decreased and the total titratable acidity (TTA) was enhanced to inhibit the growth of microorganisms. Therefore, the addition of FWG could not only enhance its nutritional properties, but also improve the flavor, quality, and structural features of bread. Moreover, it exhibited a good availability to extend the shelf life of bread.
\end{abstract}

\section{Introduction}

Wheat is one of the most significant staple food sources all over the world. Normally, the wheat kernel can be roughly divided into three parts: the endosperm, germ, and multiple histological outer layers [1], in which wheat germ is the most nutritious part being rich in protein (26\%), sugar (17\%), fat $(11 \%)$, and minerals (4\%) [2] and it also contains a high amount of vitamins and functional components, including alpha and beta-tocopherols, vitamin E, vitamin B, dietary fiber, and phytochemicals such as flavonoids and phytosterols [3].

However, the application of wheat germ is very limited in staple food. First, the shelf life of wheat germ is short because of its high content of unsaturated fatty acids and high activity of lipase and lipoxygenase, which cause rancidity more easily in storage $[4,5]$. Second, the wheat germ contains phytic acid, raffinose, and wheat germ agglutinin, which are well known as antinutritional factors. Meanwhile, the textural properties of food products could be decreased by adding wheat germ because of the high content of dietary fiber in it. The presence of wheat germ in bread products leads to technological disadvantages and inferior quality compared to bread with refined flour, such as the decrease in bread loaf volume, textural changes, and visual modifications [6]. In this case, some methods can be applied to improve the sensory characteristics of bread made of wheat flour with germ addition, such as thermal and nonthermal treatments or addition of inhibitors to inactivate enzymes [7]. Although the above approaches have been proved 
effective, there are still some disadvantages, such as too expensive, nutritional losses of wheat germ, and potential risk of synthetic food additives [8]. Therefore, the developed safe and mildly processing methods aimed to obtain high nutritional and sensory quality with a longer shelf life are more easily accepted by consumers.

In recent years, fermentation, especially probiotic fermentation, has been considered as one of the gentle, effective, and potential treatments to improve the nutritional and functional properties of cereals for food and ingredient processing [9]. At the same time of liberation of probiotic factors, the quality characteristics of wheat germ are also promoted by microbial fermentation. Rizzello et al. reported that the stabilization of wheat germ improved, while the contents of phytic acid and raffinose regarded to antinutritional factors decreased by lactic acid bacteria in sourdough [10]. And a remarkable antibacterial activity was also determined in fermented wheat germ, which exhibited a meaningful potential to extend the shelf life of food products [7]. In addition, they continued to investigate the effect of fermented wheat germ on the quality properties of white bread to confirm its positive effects on baked food [11].

This work was performed on the basis of our previous research. We found that the content of free amino acids in fermented wheat germ (FWG) increased much more than that of raw wheat germ (RWG) without fermentation, and significant increase of phytase and decrease of phytic acid were also observed [12]. The lipase and lipoxygenase activities were markedly lower by $55.3 \%$ and $76.3 \%$, respectively. After 60 days of storage, it was found that fermentation can inhibit wheat germ oxidative rancidity processing and improve storage property. Based on this, wheat germ could be suitable for staple food production as a functional ingredient after fermentation. In this paper, the fermented wheat germ with Lactobacillus plantarum dy-1 was used in bread making and the effects on the bread quality including specific volume and color, chemical and nutritional characterization, volatile flavor, texture properties, and the shelf life of bread were studied.

\section{Materials and Methods}

2.1. Preparation of Fermented Wheat Germ. Fresh wheat germ was purchased from Shandong Yongle Food Co. Ltd., China, and the raw wheat germ (RWG) was taken from the 60 mesh sieve milling. The strain used as the starter culture was Lactobacillus plantarum dy-1 (CGMCC NO. 6016), which has been isolated by authors in food biotechnology lab of Jiangsu University previously and was optimized as an effective strain for barley fermentation [13]. The bacteria was cultured in MRS (de Man, Rogosa, and Sharpe) culture medium for $12 \mathrm{~h}$. The obtained culture was centrifuged at $5000 \mathrm{rpm}$ for $10 \mathrm{~min}$, the pellet was washed with $50 \mathrm{mM}$ of sterile phosphate buffer $(\mathrm{pH}=7.0)$ for twice and resuspended in water for further use (query). $100 \mathrm{~g}$ of RWG was mixed with $60 \mathrm{~mL}$ of water and bacterial suspension. Then, the fermentation was last for $24 \mathrm{~h}$ in an incubator at $30^{\circ} \mathrm{C}$. After that, the fermentation mixture was dried at $40^{\circ} \mathrm{C}$ until the moisture content reached $10.5 \pm 0.05 \%$, and the FWG was obtained by grinding and sieving.

2.2. Preparation of Bread. The RWG and FWG levels utilized were $0 \%, 1 \%, 2 \%, 3 \%, 4 \%, 5 \%$, and $6 \%$ (based on mixed powder), and doughs were produced with $500 \mathrm{~g}$ mixed powder (wheat flour-WF), water (57\%), Angel yeast (1\%), sugar $(10 \%)$, sodium chloride $(1 \%)$, and sunflower oil $(6 \%)$. The baking bread machine was set with the same procedure for three parallel tests.

After mixing, the resulting dough was proofed at $30^{\circ} \mathrm{C}$ and $80 \%$ relative humidity for $15 \mathrm{~min}$, and then, $450 \mathrm{~g}$ of dough was weighed, molded, placed in baking pan, and proofed again at $35^{\circ} \mathrm{C}(85 \%$ relative humidity) for $65 \mathrm{~min}$. After this, it was baked to make bread at $200^{\circ} \mathrm{C}$ for $22 \mathrm{~min}$, and then cooled, packed, and stored at $25^{\circ} \mathrm{C}$ for further analysis.

\subsection{Measurement of Bread Specific Volume and Color.} The fresh breads were evaluated after $2 \mathrm{~h}$ of cooling at room temperature. Its loaf volume was measured by the mean of rape seed displacement method according to the AACC standard method 10-05 (AACC, 2008), and the specific volume of bread was expressed in volume $(\mathrm{mL} / \mathrm{g})$, which indicated volume $(\mathrm{mL}) /$ quality $(\mathrm{g})$. The $5 \mathrm{~cm}^{2}$ of bread slices were measured using a Color Quest XE colorimeter (Hunter Lab, USA) to obtain the crumb color parameters, which were expressed in Hunter's $\mathrm{L}^{*}, \mathrm{a}^{*}$, and $\mathrm{b}^{*}$ values, where $\mathrm{L}^{*}$ indicates the lightness with a value ranged from 0 to 100 representing dark to light and $\mathrm{a}^{*}$ indicates the degree of redgreen color (the higher $\mathrm{a}^{*}$ value, the more red), while $\mathrm{b}^{*}$ indicates the degree of yellow-blue color (the higher $b^{*}$ value, the more yellow).

2.4. Determination of Free Amino Acid in Bread. The values of $\mathrm{pH}$ and total titratable acidity (TTA) in bread determined according to AACC (2000) 02-52 per treatment were tested. Bread crumbs were dried and grinded at $40^{\circ} \mathrm{C} ; 15 \mathrm{~g}$ bread flour was taken, $80 \mathrm{~mL}$ of tris- $\mathrm{HCl}$ solution with a concentration of $50 \mathrm{mM}(\mathrm{pH}=8.8)$ was added, and it was magnetically stirred for $1 \mathrm{~h}$ at $4^{\circ} \mathrm{C}$, centrifuged at $3600 \mathrm{rpm}$ for $20 \mathrm{~min}$, $1 \mathrm{~mL}$ supernatant was mixed with $1 \mathrm{~mL} 3 \%$ sulfosalicylic acid, stored in the refrigerator overnight at $4{ }^{\circ} \mathrm{C}$ for protein deposition. It was then centrifuged at $3600 \mathrm{rpm}$ for $20 \mathrm{~min}$, the supernatant was filtered through a $0.22 \mu \mathrm{m}$ membrane filter, and the free amino acid content was determined by Sykam S433D Amino Acid Analyser.

2.5. Volatile Analysis of Bread. The volatile analysis was performed by an HP 6890/5973N system equipped with a quadrupole as a mass filter (Agilent Technologies, USA) and a GC column of DB-Wax $(0.25 \mathrm{~mm}$ i.d. $\times 60 \mathrm{~m}, 0.25 \mu \mathrm{m}$ film thickness) for separation. $5 \mathrm{~g}$ of bread pieces were weighed and added into a solid phase microextraction (SPME) bottle and stabilized for $10 \mathrm{~min}$ at $60^{\circ} \mathrm{C}$ in a water bath. A SPME fiber (50/30UM DVB/CAR, Supelco, USA) was inserted into the headspace of bottle and lasted for $40 \mathrm{~min}$ at $60^{\circ} \mathrm{C}$. After that, the absorbed volatiles on fiber were desorbed at $250^{\circ} \mathrm{C}$ 
TABLE 1: The comparison of specific volume and color of breads with different adding proportion.

\begin{tabular}{lcccccc}
\hline \multirow{2}{*}{ Parameter } & \multicolumn{5}{c}{ Addition $(\%)$} \\
& 0 & 2 & 3 & 4 & 5 & 6 \\
\hline Volume $(\mathrm{mL} / \mathrm{g})$ & $3.33 \pm 0.02^{\mathrm{a}}$ & $3.35 \pm 0.01^{\mathrm{a}}$ & $3.35 \pm 0.02^{\mathrm{a}}$ & $3.34 \pm 0.02^{\mathrm{a}}$ & $3.25 \pm 0.02^{\mathrm{b}}$ & $3.02 \pm 0.02^{\mathrm{c}}$ \\
$\mathrm{L} *$ & $60.55 \pm 0.12^{\mathrm{c}}$ & $60.92 \pm 0.10^{\mathrm{c}}$ & $61.22 \pm 0.09^{\mathrm{c}}$ & $62.34 \pm 0.08^{\mathrm{a}}$ & $61.99 \pm 0.05^{\mathrm{b}}$ & $62.08 \pm 0.07^{\mathrm{b}}$ \\
$\mathrm{a} *$ & $16.24 \pm 0.02^{\mathrm{c}}$ & $16.33 \pm 0.01^{\mathrm{c}}$ & $17.59 \pm 0.05^{\mathrm{b}}$ & $17.66 \pm 0.03^{\mathrm{b}}$ & $18.03 \pm 0.02^{\mathrm{a}}$ & $18.68 \pm 0.05^{\mathrm{a}}$ \\
$\mathrm{b} *$ & $35.60 \pm 0.01^{\mathrm{d}}$ & $35.87 \pm 0.02^{\mathrm{c}}$ & $36.24 \pm 0.02^{\mathrm{c}}$ & $36.98 \pm 0.03^{\mathrm{b}}$ & $37.21 \pm 0.05^{\mathrm{b}}$ & $37.91 \pm 0.04^{\mathrm{a}}$ \\
\hline
\end{tabular}

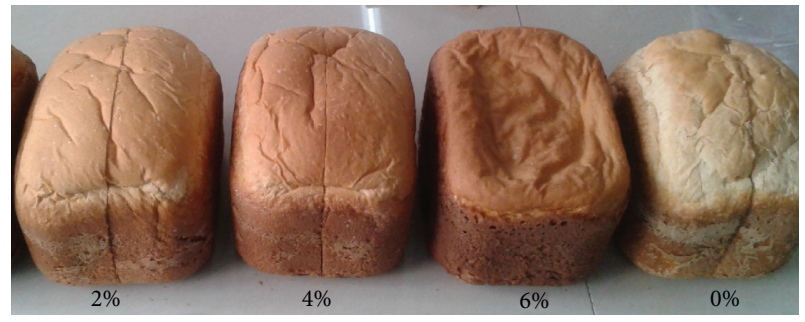

Figure 1: The effect of different addition levels of fermented wheat germ on the bread color $(2 \%, 4 \%$, and $6 \%$ wheat flour was replaced by fermented wheat germ flour).

for $2 \mathrm{~min}$ and injected under splitless mode. Then, the oven temperature was programmed from $45^{\circ} \mathrm{C}$ (hold for $6 \mathrm{~min}$ ) to $100^{\circ} \mathrm{C}$ (hold for $1 \mathrm{~min}$ ) with a rate of $20^{\circ} \mathrm{C} / \mathrm{min}$, increased to $160^{\circ} \mathrm{C}$ (hold for $2 \mathrm{~min}$ ) with a rate of $4^{\circ} \mathrm{C} / \mathrm{min}$, and finally increased up to $220^{\circ} \mathrm{C}$ (hold for $3 \mathrm{~min}$ ) with a rate of $30^{\circ} \mathrm{C} /$ min. $99.99 \%$ of helium was used as carrier gas and the constant flow was $1 \mathrm{~mL} / \mathrm{min}$.

2.6. Texture Properties Analysis of Bread. The uniform bread slices with $1.0 \mathrm{~cm}$ of thickness were obtained using a slice regulator. The firmness, springiness, and cohesiveness of bread crumbs were investigated after baking for a week, while the texture properties of fresh bread were analyzed at room temperature after cooling for $2 \mathrm{~h}$. A TA-XT2i texture analyzer (Stable Micro Systems, Godalming, U.K.) with a $5 \mathrm{~kg}$ load cell and a $25 \mathrm{~mm}$ aluminum cylindrical probe (model P/25R) was used and the analysis was carried out according to the method described by Li et al. [14] with a slight change. The sample was compressed by $40 \%$ with probe, and the pretest, test, and posttest speed were set to $1.0 \mathrm{~mm} / \mathrm{s}, 1.7 \mathrm{~mm} / \mathrm{s}$, and $1.0 \mathrm{~mm} / \mathrm{s}$, respectively. And then the firmness, springiness, and adhesiveness were quantified.

2.7. Bacterial Number Changes of Bread on the Shelf Life. The microorganism analysis was taken within 7 days to monitor the bacterial changes of bread slices wrapped in polyethylene bags and stored at $16^{\circ} \mathrm{C}$. The total number of colonies were determined according to GB 4789.2-2010.

2.8. Statistical Analysis. The measurements were performed for six replicates. The final values were recorded as mean values and analyzed by one-way repeated-measures ANOVA with SPSS 11.0. The significant differences were analyzed by Tukey's multiple-range test $(P<0.05)$.
TABle 2: The content of free amino acid of bread crumbs (mg/ $100 \mathrm{~g})$.

\begin{tabular}{lccc}
\hline $\begin{array}{l}\text { Free amino acid } \\
\text { species }\end{array}$ & WFB $^{*}$ & RWGB & FWGB \\
\hline Taurine & $0.64 \pm 0.08^{\mathrm{c}}$ & $1.21 \pm 0.05^{\mathrm{a}}$ & $0.96 \pm 0.03^{\mathrm{b}}$ \\
Citrulline & $10.35 \pm 0.08^{\mathrm{c}}$ & $14.70 \pm 0.09^{\mathrm{b}}$ & $21.80 \pm 0.09^{\mathrm{a}}$ \\
$\alpha$-Aminobutyric & $6.76 \pm 0.09^{\mathrm{c}}$ & $16.22 \pm 0.10^{\mathrm{b}}$ & $29.88 \pm 0.11^{\mathrm{a}}$ \\
acid & $38.88 \pm 0.12^{\mathrm{a}}$ & $16.01 \pm 0.13^{\mathrm{b}}$ & $6.35 \pm 0.05^{\mathrm{c}}$ \\
Leucine & & & - \\
$\beta$-Aminopropionic & $40.95 \pm 0.15^{\mathrm{a}}$ & $7.95 \pm 0.09^{\mathrm{b}}$ & - \\
acid & & & \\
$\gamma$-Aminobutyric & $5.17 \pm 0.05^{\mathrm{c}}$ & $26.64 \pm 0.07^{\mathrm{b}}$ & $28.42 \pm 0.09^{\mathrm{a}}$ \\
acid & $11.84 \pm 0.10^{\mathrm{b}}$ & $11.84 \pm 0.09^{\mathrm{b}}$ & $14.33 \pm 0.12^{\mathrm{a}}$ \\
Tryptophan & $72.55 \pm 0.34^{\mathrm{a}}$ & $69.17 \pm 0.25^{\mathrm{b}}$ & $67.60 \pm 0.33^{\mathrm{c}}$ \\
Ornithine & $1.30 \pm 0.02^{\mathrm{c}}$ & $5.95 \pm 0.05^{\mathrm{b}}$ & $13.05 \pm 0.09^{\mathrm{a}}$ \\
Lysine & $9.75 \pm 0.15^{\mathrm{c}}$ & $15.81 \pm 0.17^{\mathrm{b}}$ & $35.39 \pm 0.22^{\mathrm{a}}$ \\
Hydroxyproline & $17.72 \pm 0.19^{\mathrm{a}}$ & $17.34 \pm 0.17^{\mathrm{a}}$ & - \\
Proline & - & $5.16 \pm 0.05^{\mathrm{b}}$ & $20.39 \pm 0.11^{\mathrm{a}}$ \\
Cysteine & - & $9.81 \pm 0.06^{\mathrm{b}}$ & $20.04 \pm 0.07^{\mathrm{a}}$ \\
Arginine & - & - & $3.71 \pm 0.08$ \\
Glutamic acid & - & - & $10.04 \pm 0.11$ \\
Tyrosine & - & - & $14.89 \pm 0.05$ \\
Phenylalanine & - & - & $1.36 \pm 0.02$ \\
Histidine & & & \\
Total free amino & $215.91 \pm 4.21^{\mathrm{b}}$ & $217.81 \pm 3.28^{\mathrm{b}}$ & $288.21 \pm 3.41^{\mathrm{a}}$ \\
acid & & & \\
\hline
\end{tabular}

${ }^{*} \mathrm{WFB}=$ wheat flour bread; RWGB $=$ raw wheat germ bread; FWGB $=$ fer mented wheat germ bread. Values are the means \pm standard deviations $(n=3)$. Values followed by different lowercase letters in the same column are significantly different from each other $(P<0.05)$.

\section{Results and Discussion}

3.1. Specific Volume and Color of Bread. The bread specific volume and color parameters are shown in Table 1 and Figure 1. Bread specific volume is the ultimate parameter indicating bread-making quality. Studies revealed that there were no significant difference in terms of specific volume between the wheat bread and the bread adding maximum $4 \%$ of FWG (Table 1), whereas further increase of FWG will cause a decrease in specific volume, especially more than $5 \%$. For example, if the ratio is $6 \%$, the specific volume will decrease by $9.3 \%$. Thus, the optimum of the content of FWG was $4 \%$ in this study. The wheat germ was known to reduce bread quality, and the bread containing wheat germ had an inferior volume compared to the bread containing regular wheat flour [15]. Gluten structure changes can cause more dough characteristic changes. Because gluten can become 
TABLE 3: The pH value and TTA of bread.

\begin{tabular}{lcc}
\hline Group & $\mathrm{pH}$ & TTA $(\mathrm{mL})$ \\
\hline Wheat flour bread & $5.49 \pm 0.08$ & $3.5 \pm 0.11$ \\
Raw wheat germ bread & $5.66 \pm 0.05$ & $4.9 \pm 0.09$ \\
Fermented wheat germ bread & $4.95 \pm 0.04$ & $6.3 \pm 0.16$ \\
\hline
\end{tabular}

more soft and elastic when the degree of acidification is moderate, it can promote the increase of bread specific volume [16]. In addition, it causes some dietary fiber degradation with the effect of enzyme, thereby reducing gluten network structure damage. Some lactobacillus metabolites such as polysaccharide material have positive effects on specific volume of bread [17].

In addition, the amount of FWG more than $4 \%$ also significantly enhanced the color crumb (Table 1) and crust (Figure 1) of bread. It obviously preferred for red and yellow, which may be due to FWG which contains a large number of free amino acids (Table 2) to produce browning in the presence of reducing sugar by Maillard reaction (Ureta, 2014).

3.2. Chemical and Nutritional Analysis of Bread. The average $\mathrm{pH}$ value and TTA of bread is given in Table 3. The bread added with FWG significantly decreased the $\mathrm{pH}$ value (13\%) and increased TTA (29\%) compared to RWG as FWG can produce more organic acids such as lactic acid in the process of dough fermentation by lactic acid bacteria [18]. The $\mathrm{pH}$ value of RWG bread was similar with that of wheat flour bread, but the TTA was much larger than that of wheat flour bread. This is perhaps due to the wheat germ which can supply some kinds of organic acids that did not increase the concentration of $\mathrm{H}^{+}$. The organic acids also play an important role through esterifying with alcohols to form a pleasant flavor. In addition, the increased acidity can also inhibit bacterial and fungal contamination to prolong the shelf life of bread [11].

Free amino acids content is given in Table 2. The concentration of total free amino acids in FWG bread significantly increased compared to the wheat flour and RWG bread, that FWG increased the content of free amino acids by ca. $32 \%$ compared with that of RWG. As reported, free amino acids can improve the color and flavor of bread crust and increase the nutritional value of breads [19].

Almost all free amino acids increased in FWG bread. Citrulline, $\alpha$-aminobutyric acid, $\gamma$-aminobutyric acid (GABA), tryptophan, lysine, cysteine, and arginine concentration showed major increase and reached the concentration from ca. 1.2-fold (tryptophan) to ca. 10-fold (lysine) higher than those in wheat flour bread and to ca. 4fold (cysteine) higher than those observed in RWG bread.

$\gamma$-Aminobutyric acid (GABA), a nonprotein amino acid, is well known for its physiological activities including induction of hypotension, neurotransmission, and diuretic features [10], and it has been applied in pharmaceuticals and function foods extensively. The study showed that the content of GABA in the bread of wheat flour was very low, with only $5.17 \mathrm{mg} / 100 \mathrm{~g}$, while it increased markedly in the bread of RWG and FWG to 5.2-fold and 5.5-fold,
TABLE 4: The volatile flavor components in different groups of bread.

\begin{tabular}{|c|c|c|c|c|c|}
\hline \multirow{2}{*}{ No. } & \multirow{2}{*}{$\begin{array}{l}\text { Time } \\
(\min )\end{array}$} & \multirow{2}{*}{ Compounds } & \multicolumn{3}{|c|}{ Relative peak area (\%) } \\
\hline & & & WFB* & RWGB & FWGB \\
\hline 1 & 8.77 & Isovaleraldehyde & 0.51 & 0.80 & 0.56 \\
\hline 2 & 9.18 & Ethanol & 41.41 & 29.78 & 29.87 \\
\hline 3 & 9.85 & Vinyl acetate & 0.97 & - & 0.35 \\
\hline 4 & 12.02 & N-Hexanal & - & 2.43 & 2.57 \\
\hline 5 & 12.28 & 2-Methyl-1-propanol & 1.01 & 2.85 & 3.21 \\
\hline 6 & 13.78 & Dodecane & 0.21 & - & - \\
\hline 7 & 13.85 & 3-Methyl-1-butanol & 5.65 & 6.77 & 7.65 \\
\hline 8 & 14.00 & Heptane & 0.60 & 0.82 & 0.25 \\
\hline 9 & 14.19 & Dipentene & 0.59 & - & - \\
\hline 10 & 14.61 & Isoamyl alcohol & 18.29 & 13.54 & 19.46 \\
\hline 11 & 14.79 & 2-n-Pentylfuran & 0.46 & 1.46 & 0.55 \\
\hline 12 & 15.43 & 1-Pentanol & 0.34 & - & - \\
\hline 13 & 16.54 & $\begin{array}{l}\text { 3-Hydroxy-2- } \\
\text { butanone }\end{array}$ & 2.92 & 3.08 & 4.83 \\
\hline 14 & 17.21 & 2-Heptenal & 0.72 & - & 0.29 \\
\hline 15 & 17.58 & N-Hexanol & - & 5.40 & 1.01 \\
\hline 16 & 17.59 & 4-Methyl-1-pentanol & - & - & 2.09 \\
\hline 17 & 17.62 & $\begin{array}{c}\text { N-Hexyl } \\
\text { chloroformate }\end{array}$ & 2.95 & - & - \\
\hline 18 & 18.67 & Nonanal & 1.67 & - & 0.55 \\
\hline 19 & 19.56 & Octanoate & 0.63 & - & 1.02 \\
\hline 20 & 19.94 & Acetic acid & 1.36 & 0.69 & 1.63 \\
\hline 21 & 20.04 & Heptanol & - & 1.08 & 0.45 \\
\hline 22 & 20.48 & Furfural & 0.94 & 6.41 & 7.27 \\
\hline 23 & 20.88 & $2 \mathrm{E}$ & 0.43 & 0.56 & - \\
\hline 24 & 21.63 & $\begin{array}{l}\text { 4-Methyl-1,3- } \\
\text { heptadiene }\end{array}$ & - & 0.43 & - \\
\hline 25 & 22.28 & Benzaldehyde & 3.43 & 4.34 & 2.57 \\
\hline 26 & 22.41 & 2-nonenal & 0.67 & 0.70 & 0.95 \\
\hline 27 & 22.86 & $\begin{array}{l}\text { 2-Methylpropionic } \\
\text { acid }\end{array}$ & 8.50 & 4.21 & 3.22 \\
\hline 28 & 23.17 & 2,3-Butanediol & 0.30 & - & 0.30 \\
\hline 29 & 24.05 & $\begin{array}{l}\text { 1,3-Propanediol } \\
\text { diacetate }\end{array}$ & - & - & 0.55 \\
\hline 30 & 25.07 & 3-Methyl butyric acid & 0.21 & 0.55 & 0.87 \\
\hline 31 & 26.21 & Cis-3-nonenol & - & 1.62 & 0.45 \\
\hline 32 & 27.76 & Naphthalene & 0.52 & 0.83 & - \\
\hline 33 & 30.07 & Phenylethanol & 3.16 & 4.89 & 5.26 \\
\hline
\end{tabular}

${ }^{*} \mathrm{WFB}=$ wheat flour bread; RWGB $=$ raw wheat germ bread; FWGB $=$ fermented wheat germ bread.

respectively. GABA was found at highest concentrations in wheat germ, but was not determined in the wheat flour, and it may be attributed to endogenous enzymes effect [20]. In addition, many studies proved that lactic acid bacteria have the capacity for GABA synthesis in different fermented food $[21,22]$.

The concentration of lysine in the FWG bread was ca. $13.05 \mathrm{mg} / 100 \mathrm{~g}$, while it was very low with only $1.3 \mathrm{mg} / 100 \mathrm{~g}$ in the wheat flour bread; FWG bread had 10 -fold increased concentration of lysine with respect to wheat flour bread and 4.6-fold with respect to RWG bread. Lysine is an essential amino acid, which is limited in foods of plant origin, especially in cereals [23]; therefore, the addition of FWG can improve the nutritional characteristics of breads.

Cysteine can change protein molecule structure through the internal disulfide bond to promote the formation of 


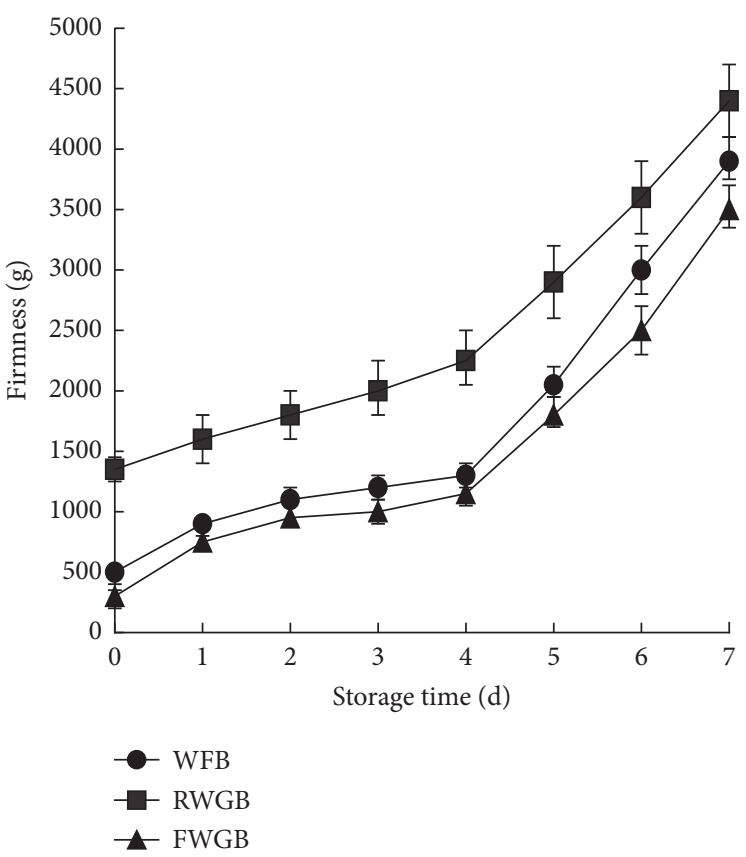

(a)

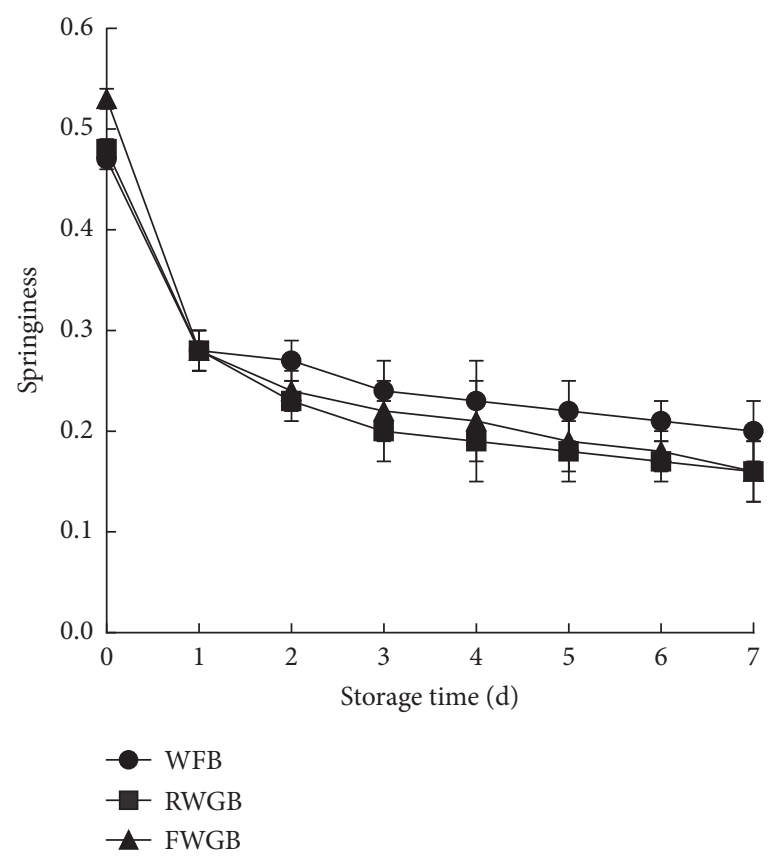

(b)



(c)

FIGURE 2: The texture properties (firmness, springiness, and adhesiveness) of bread during storage. WFB = wheat flour bread; RWGB $=$ raw wheat germ bread; FWGB $=$ fermented wheat germ bread. Values are the means \pm standard deviations $(n=3)$.

gluten. It is often used as a modifier of baked goods. The concentration of cysteine in the FWG bread was ca. $20.39 \mathrm{mg} / 100 \mathrm{~g}$, and it increased to ca. 4.0 -fold than that in the RWG bread.

3.3. Flavor Analysis of Bread. The profile of volatile compounds is given in Table 4 , and a total of 33 volatile compounds were identified in the samples. About 26, 22, and 26 volatile compounds were identified by GC-MS in the wheat flour bread, RWG bread, and FWG bread, respectively. Those compounds were mainly alcohols, aldehydes, acids, ketones, esters, and alkanes. Flavor is undoubtedly the most important attribute determining consumption as a combination of smell and taste. Volatile flavor compounds have been extensively studied in bread products, but sourdough volatile compounds have been less studied, especially in the bread of sourdough fermented wheat germ [24, 25]. 


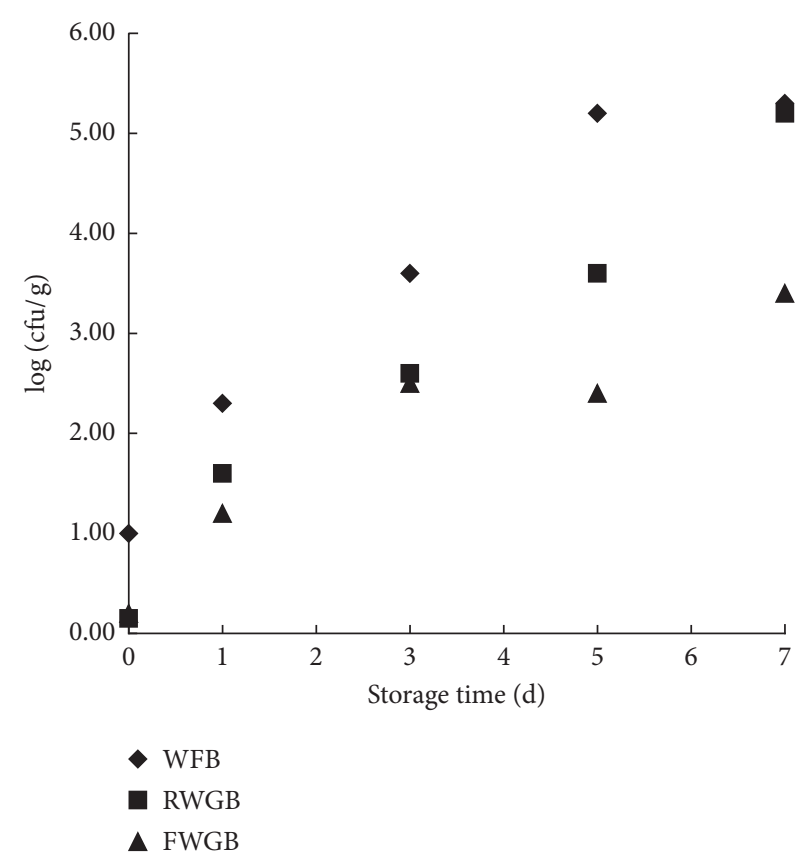

FIGURE 3: The count of bacteria in bread crumbs during storage. $\mathrm{WFB}=$ wheat flour bread; $\mathrm{RWGB}=$ raw wheat germ bread; $\mathrm{FWGB}=$ fermented wheat germ bread. Values are the mean$\mathrm{s} \pm$ standard deviations $(n=3)$.

As shown in Table 4, alcohols and aldehydes were the most abundantly identified compounds whose content was ca. $80 \%$ of the total peak area. The contents of ethanol were $41.41 \%$, $29.78 \%$, and $29.87 \%$ for wheat flour bread, RWG bread, and FWG bread, respectively. The $95 \%$ of fermentable sugars was transformed into ethanol and carbon dioxide by yeast in flour, and it can lead to higher ethanol content. The contents of other alcohols except ethanol were $23.53 \%, 36.71 \%$, and $39.88 \%$ for wheat flour bread, RWG bread, and FWG bread, respectively. The remarkable compounds were isoamyl alcohol, 3-methyl1-butanol, phenylethanol, 2-methyl-1-propanol, etc. It was reported that these alcohols were probably generated from the degradation of hydroperoxides, which were originated from unsaturated fatty acids [7].

Another abundant compounds were aldehydes, the content of aldehydes were $7.94 \%, 14.68 \%$, and $14.76 \%$ for wheat flour bread, RWG bread, and FWG bread, respectively. Also, aldehydes were probably synthesized by oxidative reactions. Moreover, the most abundant volatile compound was furfural, which presented $49 \%$ in the total aldehydes in FWG bread, and it increased by 7.73 -fold and 6.82-fold in the FWG and RWG bread, respectively, compared with that in wheat flour bread. Only $\mathrm{N}$-hexanal was identified in RWG bread (16.55\% of the total aldehydes) and FWG bread (17.41\% of the total aldehydes), which may be attributed to the fermentation of wheat germ by lactic acid bacteria or bread yeast.

Some important flavor compounds (phenylethanol, furfural, 3-methyl butyric acid, 3-hydroxy-2-butanone, and 3-methyl-1-butanol) were also increased in the RWG and FWG bread compared with the wheat flour bread, which result in more malty, milk, and sweet aroma.
3.4. Texture Properties of Breads during Storage. The texture properties (firmness, springiness, and adhesiveness) of breads with added wheat flour, RWG, and FWG are shown in Figure 2. After baking, the firmness, representing the peak force of the first compression on the sample, was the highest in the RWG bread compared with that in the wheat flour bread or FWG bread. During 7 days of storage, the value of firmness in different groups gradually increased, and it was still obviously higher in the RWG bread than that in the wheat flour bread or FWG bread. Springiness and adhesiveness were the highest in the FWG bread than that in the wheat flour bread or RWG bread ( $0 \mathrm{~d}$ ); it decreased gradually after one day of storage, and the springiness and adhesiveness were slightly lower in the FWG or RWG bread than that in the wheat flour bread. In general, adding FWG can decrease the staling rate and partially improve the texture of bread. However, the addition of RWG produced adverse effects on the bread quality.

Firmness is one of the parameters used to evaluate staling, and fermented wheat germ can effectively help to delay the staling of bread. It has been reported that fermentation promotes lipid hydrolysis, leading to the production of mono and diglycerides, which confirmed the effectiveness in slower staling of bread.

It has been reported that high amounts of glutathione were present in the raw wheat germ and glutathione can weaken the gluten network by breaking disulfide bonds [26] However, fermentation significantly decreased the level of glutathione because Lactobacillus plantarum can utilize glutathione as the amino acid source for their growth $[27,28]$.

3.5. Total Bacterial Count of Bread during Storage. The bacterial counts in crumbs of bread added with wheat flour, RWG, and FWG are shown in Figure 3. The number of bacteria had a sharp increase and reached $2.41 \times 10^{5} \mathrm{cfu} / \mathrm{g}$ in the wheat flour bread after 7 days, while the final amount of bacteria was $3.23 \times 10^{3} \mathrm{cfu} / \mathrm{g}$ in the FWG bread at the 7 th day of storage. During storage, the number of bacteria was lower in the FWG bread than that in the wheat flour and RWG bread. It may be because of the decrease in the $\mathrm{pH}$ value and presence of some antimicrobial active substances in FWG, which endowed an antibacterial effect on bread. Therefore, it would be helpful to prolong the shelf life of bread.

\section{Conclusions}

As a nutritious and important by-product of wheat processing, wheat germ has great potential in functional food and ingredient development. Fermentation could be an effective treatment to promote the processing adaptability and extend the application of wheat germ as a food ingredient. In this paper, wheat germ was fermented by Lactobacillus plantarum dy-1, and the FWG was obtained and used as a functional ingredient added to bread. The effect on bread quality with addition of FWG was evaluated, and the results indicated that $4 \%$ of FWG addition was helpful to keep the bread specific volume. Besides, the 
decrease of $\mathrm{pH}$ value and TTA could inhibit bacteria growth and prolong the shelf life of bread. In addition, the total free amino acids content increased ca. 1.32-fold, which contributed to the flavor and color of bread. Therefore, more variety and higher content of volatile flavor compounds were found in FWG bread compared with RWG bread, mainly alcohols and aldehydes. Moreover, it also decreased the firmness, especially retention of softness during storage, but did not improve the springiness and adhesiveness. Based on the above results, it is reasonable to believe that the fermented wheat germ could be a suitable functional ingredient with the capacity of enhancing nutritional, texture, and flavor properties of bread.

\section{Data Availability}

All data generated or analyzed during this study are included in this article.

\section{Conflicts of Interest}

The authors declare that they have no conflicts of interest.

\section{Acknowledgments}

This research was supported by National Natural Science Foundation of China (31701605) and Key Research and Development Project of Zhenjiang (NY2017009).

\section{References}

[1] P. Shewry, Principles of Cereal Science and Technology, Academic Press, Cambridge, MA, USA, 2010.

[2] X. Bin and D. Ying, "Present situation and trends of wheat germ industrialization developing," Transactions of the Chinese Society of Agricultural Engineering, vol. 2011, no. 14, 2011.

[3] W. U. Ding, C. J. Liu, and C. P. Liu, "Function and extraction of health factors in wheat germ," Food Science, vol. 26, no. 9, pp. 615-618, 2005.

[4] O. Sjövall, T. Virtalaine, A. Lapveteläinen, and H. Kallio, "Development of rancidity in wheat germ analyzed by headspace gas chromatography and sensory analysis," Journal of Agricultural and Food Chemistry, vol. 48, no. 8, pp. 3522-3527, 2000.

[5] B. Li, L. Zhao, H. Chen et al., "Inactivation of lipase and lipoxygenase of wheat germ with temperature-controlled short wave infrared radiation and its effect on storage stability and quality of wheat germ oil," PLoS One, vol. 11, no. 12, Article ID e0167330, 2016.

[6] S. Hemdane, P. J. Jacobs, E. Dornez, J. Verspreet, J. A. Delcour, and C. M. Courtin, "Wheat (Triticum aestivum L.) bran in bread making: a critical review," Comprehensive Reviews in Food Science and Food Safety, vol. 15, no. 1, pp. 28-42, 2016.

[7] C. G. Rizzello, L. Nionelli, R. Coda, M. De Angelis, and M. Gobbetti, "Effect of sourdough fermentation on stabilisation, and chemical and nutritional characteristics of wheat germ," Food Chemistry, vol. 119, no. 3, pp. 1079-1089, 2010.

[8] V. M. Paradiso, C. Summo, A. Trani, and F. Caponio, "An effort to improve the shelf life of breakfast cereals using natural mixed tocopherols," Journal of Cereal Science, vol. 47, no. 2, pp. 322-330, 2008.
[9] K. Katina and K. Poutanen, "Nutritional aspects of cereal fermentation with lactic acid bacteria and yeast," in Handbook on Sourdough Biotechnology, Springer, Berlin, Germany, 2013.

[10] C. G. Rizzello, A. Cassone, R. Di Cagno, and M. Gobbetti, "Synthesis of angiotensin I-converting enzyme (ACE)-inhibitory peptides and $\gamma$-aminobutyric acid (GABA) during sourdough fermentation by selected lactic acid bacteria," Journal of Agricultural and Food Chemistry, vol. 56, no. 16, pp. 6936-6943, 2008.

[11] C. G. Rizzello, A. Cassone, R. Coda, and M. Gobbetti, “Antifungal activity of sourdough fermented wheat germ used as an ingredient for bread making," Food Chemistry, vol. 127, no. 3, pp. 952-959, 2011.

[12] Y. X. Wei, Y. Dong, and X. H. Zhou, "Improvement of nutritional qualities and storage characteristics of wheat germ by lactic acid bacteria fermentation," Modern Food Science \& Technology, vol. 30, no. 4, pp. 147-153, 2014.

[13] J. Zhang, X. Xiao, Y. Dong, L. Shi, T. Xu, and F. Wu, "The antiobesity effect of fermented barley extracts with Lactobacillus plantarum dy-1 and Saccharomyces cerevisiae in diet-induced obese rats," Food \& Function, vol. 8, no. 3, pp. 1132-1143, 2017.

[14] Z. Li, Y. Dong, X. Zhou, X. Xiao, Y. Zhao, and L. Yu, "Dough properties and bread quality of wheat-barley composite flour as affected by $\beta$-glucanase," Cereal Chemistry Journal, vol. 91, no. 6, pp. 631-638, 2014.

[15] Y. Pomeranz, M. Shogren, and K. Finney, "Fiber in breadmaking-effects on functional properties," Cereal Chemistry, vol. 51, pp. 25-41, 1977.

[16] C. I. Clarke, T. J. Schober, and E. K. Arendt, "Effect of single strain and traditional mixed strain starter cultures on rheological properties of wheat dough and on bread quality," Cereal Chemistry Journal, vol. 79, no. 5, pp. 640-647, 2002.

[17] M. Brandt, K. Roth, and W. Hammes, "Effect of an exopolysaccharide produced by Lactobacillus sanfranciscensis LTH1729 on dough and bread quality," in Sourdough from Fundamentals to Application, Vol. 80, Vrije Universiteit Brussels (VUB), Brussels, Belgium, 2003.

[18] M. Prückler, C. Lorenz, A. Endo et al., "Comparison of homoand heterofermentative lactic acid bacteria for implementation of fermented wheat bran in bread," Food Microbiology, vol. 49, pp. 211-219, 2015.

[19] P. Schieberle, "The role of free amino acids present in yeast as precursors of the odorants 2-acetyl-1-pyrroline and 2-acetyltetrahydropyridine in wheat bread crust," Zeitschrift fur Lebensmittel-Untersuchung und -Forschung, vol. 191, no. 3, pp. 206-209, 1990.

[20] H. Nagaoka, "Treatment of germinated wheat to increase levels of GABA and IP6 catalyzed by endogenous enzymes," Biotechnology Progress, vol. 21, no. 2, pp. 405-410, 2008.

[21] Y. R. Cho, J. Y. Chang, and H. C. Chang, "Production of gamma-aminobutyric acid (GABA) by Lactobacillus buchneri isolated from kimchi and its neuroprotective effect on neuronal cells," Journal of Microbiology and Biotechnology, vol. 17, no. 1, pp. 104-109, 2007.

[22] M. Diana, A. Tres, J. Quílez, M. Llombart, and M. Rafecas, "Spanish cheese screening and selection of lactic acid bacteria with high gamma-aminobutyric acid production," LWT-Food Science and Technology, vol. 56, no. 2, pp. 351355, 2014.

[23] M. Brestenský, S. Nitrayová, J. Heger et al., "Methods for determination reactive lysine in heat-treated foods and feeds," The Journal of Microbiology, Biotechnology and Food Sciences, vol. 4, no. 1, 2014 
[24] I. H. Cho and D. G. Peterson, "Chemistry of bread aroma: a review," Food Science and Biotechnology, vol. 19, no. 3, pp. 575-582, 2010.

[25] C. Pétel, B. Onno, and C. Prost, "Sourdough volatile compounds and their contribution to bread: a review," Trends in Food Science \& Technology, vol. 59, pp. 105-123, 2016.

[26] D. Every, S. C. Morrison, L. D. Simmons, and M. P. Ross, "Distribution of glutathione in millstreams and relationships to chemical and baking properties of flour," Cereal Chemistry Journal, vol. 83, no. 1, pp. 57-61, 2006.

[27] E. Hullett and R. Stern, "Biological elimination of glutathione from wheat germ and flours used in bread making," Cereal Chemistry, vol. 18, pp. 561-572, 1941.

[28] A. Marti, L. Torri, M. C. Casiraghi et al., "Wheat germ stabilization by heat-treatment or sourdough fermentation: effects on dough rheology and bread properties," LWT-Food Science and Technology, vol. 59, no. 2, pp. 1100-1106, 2014. 